\title{
High sensitivity and negative predictive value of the DETECT algorithm for an early diagnosis of pulmonary arterial hypertension in systemic sclerosis: application in a single center
}

Alfredo Guillén-Del Castillo ${ }^{1 *}$, Eduardo L. Callejas-Moraga', Gabriela García², José F. Rodríguez-Palomares², Antonio Román ${ }^{3}$, Cristina Berastegui ${ }^{3}$, Manuel López-Meseguer ${ }^{3}$, Enric Domingo ${ }^{2}$, Vicente Fonollosa-Plá ${ }^{1}$ and Carmen Pilar Simeón-Aznar ${ }^{1}$

\begin{abstract}
Background: Pulmonary arterial hypertension (PAH) is one of the most relevant causes of death in systemic sclerosis. The aims of this study were to analyse the recently published DETECT algorithm comparing it with European Society of Cardiology/European Respiratory Society (ESC/ERS) 2009 guidelines: as screening of PAH; (2) identifying median pulmonary arterial pressure (mPAP) $\geq 21 \mathrm{mmHg}$; and (3) determining any group of pulmonary hypertension (PH).

Methods: Eighty-three patients fulfilling LeRoy's systemic sclerosis diagnostic criteria with at least right heart catheterization were studied retrospectively. Clinical data, serological biomarkers, echocardiographic and hemodynamic features were collected. SPSS 20.0 was used for statistical analysis.

Results: According to right heart catheterization findings, 35 patients with PAH and 28 with no PH met the standards for DETECT algorithm analysis: $27.0 \%$ of patients presented with functional class III/IV. Applying DETECT, the sensitivity was $100 \%$, specificity $42.9 \%$, the positive predictive value $68.6 \%$ and the negative predictive value 100\%, whereas employing the ESC/ERS guidelines these were $91.4 \%, 85.7 \%, 88.9 \%$ and $89.3 \%$, respectively. There were no missed diagnoses of PAH using DETECT compared with three patients missed (8.5\%) using ESC/ERS guidelines. The DETECT algorithm also showed greater sensitivity and negative predictive value to identify patients with $\mathrm{mPAP} \geq 21 \mathrm{mmHg}$ or with any type of $\mathrm{PH}$.

Conclusions: The DETECT algorithm is confirmed as an excellent screening method due to its high sensitivity and negative predictive value, minimizing missed diagnosis of PAH. DETECT would be accurate either for early diagnosis of borderline mPAP or any group of $\mathrm{PH}$.
\end{abstract}

Keywords: Systemic sclerosis, Pulmonary arterial hypertension, Echocardiography, Screening tools

\footnotetext{
* Correspondence: alguille@vhebron.net; alguillen@vhebron.net

${ }^{1}$ Department of Systemic Autoimmune Diseases, Hospital Universitari Vall

d'Hebron, Universitat Autònoma de Barcelona, Passeig Vall d'Hebron 119-129,

PC: 08035 Barcelona, Spain

Full list of author information is available at the end of the article
} 


\section{Background}

Systemic sclerosis (SSc) is an autoimmune disease characterized by inflammation and autoimmunity, aberrant tissue reparation with excessive extracellular matrix deposition and altered vascular regeneration and endothelial injury $[1,2]$. Pulmonary arterial hypertension (PAH) is one of the most severe complications in patients with SSc, in whom the prevalence is $10 \%$ as diagnosed by right heart catheterization (RHC) [3, 4]. PAH has a major negative impact on survival and has become one of the leading causes of SSc-related deaths [5-7]. The outcome of this disease unfortunately is poor, with a $51 \%$ survival rate at 5 years of diagnosis even after the introduction of potent vasodilatator agents [8]. Despite SSc being a well-known risk factor for developing $\mathrm{PAH}$, there are still delays in diagnosing $\mathrm{PAH}$ and consequently more than $80 \%$ of patients present with World Health Organization (WHO) functional class III or IV at this point [8].

A French nationwide prospective multicentre study aimed to compare early PAH diagnosis using Doppler echocardiography prior to referral for RHC compared with routine clinical practice [9]. Later, the authors demonstrated prompt PAH identification in patients with lower functional classes of disease and subsequently a fourfold superior survival ratio [10]. The European Society of Cardiology and the European Respiratory Society (ESC/ERS) guidelines published in 2009 [11] recommended echocardiography in symptomatic patients. RHC was carried out if the tricuspid regurgitant velocity (TRV) was $\geq 3.4 \mathrm{~m} / \mathrm{s}$, TRV between $2.8-3.4 \mathrm{~m} / \mathrm{s}$ with symptoms or TRV $\leq 2.8 \mathrm{~m} / \mathrm{s}$ with symptoms plus additional echocardiographic variables suggestive of $\mathrm{PH}$.

Recently, Coghlan et al. reported the first evidencebased algorithm for the screening of $\mathrm{PAH}$ in SSc (DETECT) [12]. The DETECT algorithm is a tool to identify patients with $\mathrm{PAH}$ in the asymptomatic stages, through the study of clinical variables, pulmonary function tests, immunological, biological, electrocardiographic and finally echocardiographic parameters. The authors demonstrated higher sensitivity of $\mathrm{PAH}$ detection than that achieved using the ESC/ERS 2009 guidelines.

The main aim of this study was to determine the value of the DETECT algorithm in a different population of patients with SSc from that studied in the original work and to compare it with the ESC/ERS 2009 guidelines. Other objectives were to ascertain the ability of DETECT to predict median pulmonary arterial pressure (mPAP) $\geq 21 \mathrm{mmHg}$ or to predict patients with pulmonary hypertension $(\mathrm{PH})$ versus patients with no $\mathrm{PH}$.

\section{Methods}

\section{Patients}

Eighty-three patients with SSc who had undergone at least one $\mathrm{RHC}$ were studied retrospectively. The RHC was indicated due to suspicion of PAH after undergoing an annual complete pulmonary function test and annual echocardiography as routine monitoring of SSc. The reasons for carrying out the $\mathrm{RHC}$ in our population were the presence of right ventricular systolic pressure (RVSP) $>36 \mathrm{mmHg}$ plus a forced vital capacity/diffusing capacity for carbon monoxide (FVC/DLCO) ratio >1.6 in 35 patients, 34 patients had RVSP $>36 \mathrm{mmHg}, 8$ patients had a FVC/DLCO ratio $>1.6$ and 6 patients suffered exclusively from progressive unexplained dyspnoea. All patients fulfilled LeRoy's SSc diagnostic criteria [13], and 80 patients also met the American College of Rheumatology/European League Against Rheumatism (ACR/EULAR) 2013 classification criteria [14]. The duration of disease was more than 3 years from the first non-Raynaud's phenomenon symptom in all cases. For validation of the DETECT algorithm, four patients were excluded as they presented with a FVC lower than the $40 \%$ predicted value, and another patient was excluded who did not meet the inclusion criteria due to $\mathrm{DLCO} \geq 60 \%$.

\section{Comparisons of the DETECT algorithm and the ESC/ERS 2009 guidelines}

Three different scenarios were conducted for the comparison of the DETECT algorithm with the ESC/ERS 2009 guidelines: First, 35 patients diagnosed with PAH and 28 with no $\mathrm{PH}$ after undergoing $\mathrm{RHC}$ were selected for the application of the DETECT algorithm (see Fig. 1). Second, these 63 patients were used to explore the capacity of both screening tests to identify mPAP $\geq 21 \mathrm{mmHg}$ (both borderline mPAP and PAH). Third, with neither inclusion nor exclusion criteria 52 patients diagnosed with $\mathrm{PH}$ and 31 with no $\mathrm{PH}$ were selected to investigate the detection of any sort of $\mathrm{PH}$.

\section{Data collection}

Data from the first available RHC of each patient were revised. $\mathrm{PH}$ was defined as $\mathrm{mPAP} \geq 25 \mathrm{mmHg}$ in $\mathrm{RHC}$, and was classified in the following groups: WHO group 1 or PAH was defined if pulmonary artery wedge pressure (PAWP) was $\leq 15 \mathrm{mmHg}$ and pulmonary vascular resistance (PVR) was >3 Wood units in RHC [15]; WHO group 2 or $\mathrm{PH}$ due to left heart disease, if PAWP was $>15 \mathrm{mmHg}$; WHO group 3 or $\mathrm{PH}$ due to interstitial lung disease (ILD) if PAWP was $\leq 15 \mathrm{mmHg}$ and predicted FVC $<60 \%$ or if the extent of interstitial disease was identified as moderate-severe on high-resolution computed tomography (HRCT) [12]. Borderline mPAP (BoPAP) was considered if mPAP was between 21 and $24 \mathrm{mmHg}$, with PAWP $\leq 15 \mathrm{mmHg}$ and if there was no ILD or the FVC was $>60 \%$ [16].

Based on the extent of skin involvement, patients were divided into those with diffuse cutaneous SSc (dcSSc) if 


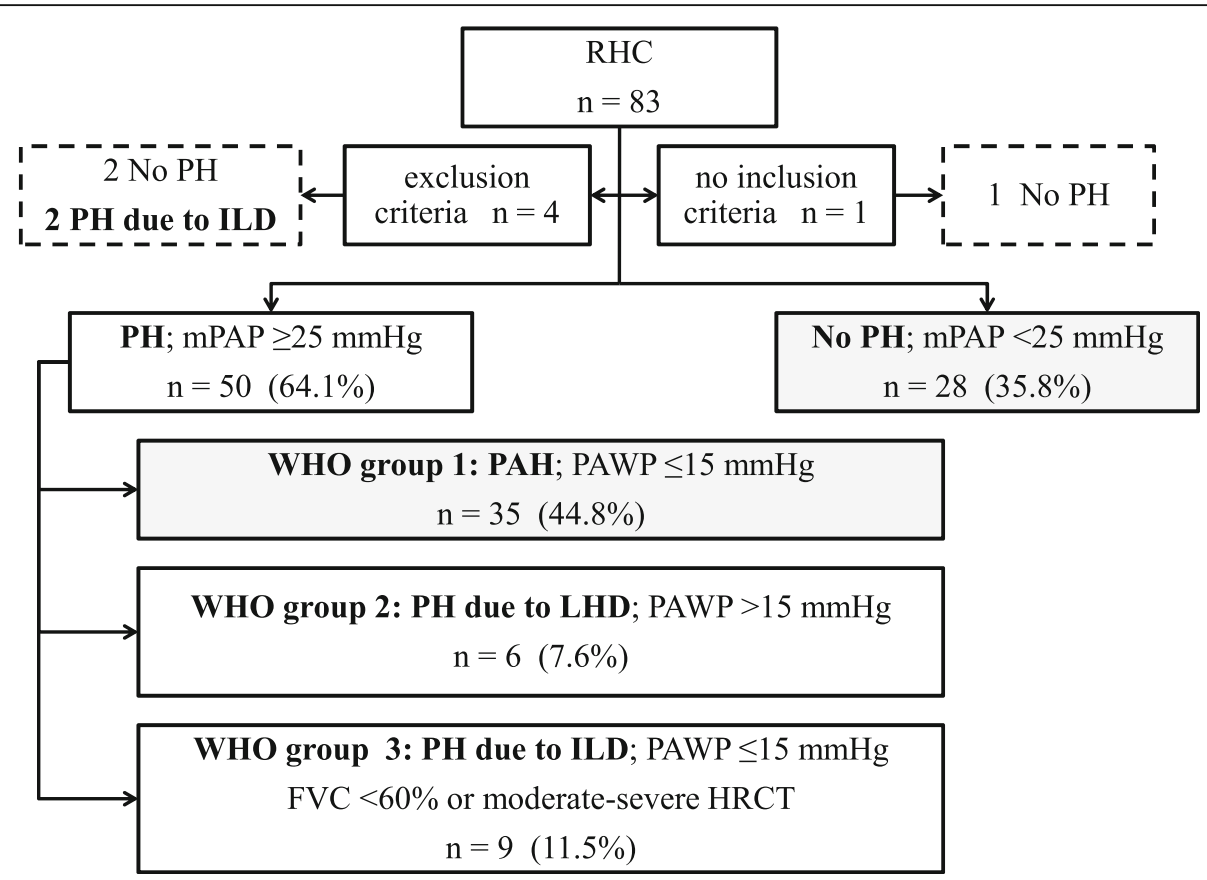

Fig. 1 Flow of patients in the study population. Eighty-three patients with systemic sclerosis had at least one right heart catherization (RHC), which was revised retrospectively. Four patients were excluded due to the exclusion criteria (all patients had forced vital capacity $(F V C)<40 \%)$, and another patient was excluded due to not meeting the inclusion criteria, who had a diffusing capacity for carbon monoxide (DLCO) $\geq 60 \%$. Patients with pulmonary arterial hypertension $(P A H)$ and patients without pulmonary hypertension (no $P H)(n=63)$ were selected for the following studies: (1) validation of the DETECT algorithm for screening of PAH and (2) identification of patients with median pulmonary arterial pressure (mPAP) $\geq 21 \mathrm{mmHg}$ and (3) determination of any group of PH (all patients $(n=83)$ were included in this study). WHO World Health Organization, PAWP pulmonary artery wedge pressure, LHD left heart disease, ILD interstitial lung disease, $H R C T$ high-resolution computed tomography

thickening of the skin was distal and proximal to the elbows or knees, limited cutaneous SSc (lcSSc) if the affected skin did not exceed this limit proximally and sine scleroderma systemic sclerosis (ssSSc) if no skin thickening was present [17]. The disease onset was described as the date of the first symptom attributable to SSc, including Raynaud's phenomenon (RP), although the time from the first symptom excluding RP also was analysed. All data were collected at the time of RHC.

The presence of telangiectasias, past or current digital ulcers (DU) and past history of scleroderma renal crisis (SRC) was recorded. ILD was defined as radiological evidence of interstitial disease on HRCT. Cardiac involvement was defined as current or past history of pericardial effusion, left ventricular ejection fraction (LVEF) $<50 \%$ and ischaemic heart disease with no cardiovascular risk factor or conduction abnormalities.

Antinuclear antibodies (ANA) were evaluated by indirect immunofluorescence (IIF) assay using HEp-cell line 2. Anticentromere antibodies (ACA) were described by IIF or commercial line blot assay to centromere proteins A and B (EUROLINE Systemic Sclerosis (Nucleoli) Profile (IgG), Euroimmun, Germany). Anti-topoisomerase I antibodies were determined by enzyme-linked immunosorbent assay.
Demographics, cardiovascular risk factors, anthropometrical data, complete pulmonary function test (PFT), 6-minute walking distance (6MWD), WHO-functional class, laboratory data including serum urate, $\mathrm{N}$-terminal pro-brain natriuretic peptide (NT-proBNP) and right axis deviation in electrocardiography (ECG) were registered. Echocardiography included the determination of left ventricular ejection fraction (LVEF), right atrium (RA) area, tricuspid annular plane systolic excursion (TAPSE), tricuspid regurgitation velocity (TRV) and RVSP.

RHC details consisted of mPAP, PAWP, right atrial pressure (RAP), transpulmonary pressure gradient (TPG), cardiac output (CO), pulmonary vascular resistance (PVR), systemic vascular resistance (SVR), mixed venous oxygen saturation $(\mathrm{SvO} 2)$ measured in pulmonary artery and arterial oxygen saturation $(\mathrm{SaO} 2)$ measured in arterial blood gas analysis.

The application of the DETECT algorithm was conducted in two steps through the website PAH risk calculator (http://detect-pah.com) [18], the first step for referring the patient for echocardiography and the second for carrying out RHC [12]. The indication of RHC following ESC/ERS 2009 guidelines was considered if: (1) TRV was $>3.4 \mathrm{~m} / \mathrm{s}$; or (2) TRV was $>2.8$ to $\leq 3.4 \mathrm{~m} / \mathrm{s}$, 
with symptoms (undue dyspnoea or fatigue, chest pain, near syncope or signs of right heart failure); or (3) TRV was $\leq 2.8 \mathrm{~m} / \mathrm{s}$, with symptoms and additional echocardiographic variables suggestive of $\mathrm{PH}$.

\section{Statistical analysis}

Qualitative data were expressed as the mean and standard deviation (SD) after checking the data using the normal distribution test, and non-normally distributed qualitative variables were described as the median and interquartile range (IQR). To assess whether there were statistically significant differences, Student's $t$ test or the Mann-Whitney $U$ test were used according to the result of the normal distribution test. Categorical variables were analysed by the chi-square test and Fisher's exact test. The 95\% confidence intervals (CIs) were calculated for sensitivity, specificity, positive predictive value (PPV) and negative predictive value (NPV). A $p$ value $<0.05$ was considered significant. Statistical analysis was conducted using SPSS 20.0 for Windows (SPSS Inc., Chicago, IL, USA).

\section{Results}

\section{Baseline characteristics}

Comparing the indications for RHC in 83 patients, the proportions of patients diagnosed with $\mathrm{PH}$ were 24/35 patients $(68.5 \%)$ with RVSP $>36 \mathrm{mmHg}$ plus FVC/DLCO ratio $>1.6,23 / 34$ patients $(67.6 \%)$ with RVSP $>36 \mathrm{mmHg}$, $4 / 8$ patients (50.0\%) with FVC/DLCO ratio $>1.6$ and $1 / 6$ patients $(16.6 \%)$ with progressive unexplained dyspnoea. Two the four patients who were excluded had $\mathrm{PH}$ due to ILD. Following the RHC results in the 78 patients who fulfilled the inclusion criteria and did not meet the exclusion criteria, $\mathrm{PH}$ was identified in 50 patients (64.1\%) and $\mathrm{PH}$ was ruled out in the other 28 subjects (35.8\%), although 14 of them had BoPAP with mPAP between 21 and $24 \mathrm{mmHg}$ (Fig. 1). According to PH classification, 35 patients (44.8\%) were diagnosed with PAH, 6 (7.6\%) had $\mathrm{PH}$ due to left heart disease and 9 (11.5\%) had PH due to ILD. Sixty-three patients with PAH and without $\mathrm{PH}$ were selected for DETECT algorithm analysis.

The baseline characteristics of the selected patients with SSc are summarized in Table 1. There were 59 women and 4 men, the mean \pm SD age at RHC was 62.4 \pm 11.6 years. Based on skin involvement, lcSSc was the most frequent cutaneous subtype in 45 patients (71.4\%), 10 patients $(15.9 \%)$ had dcSSc and 8 patients (12.7\%) had ssSSc. The mean time from the first SSc symptom including RP was $18.6 \pm 12.3$ years, while for the time from first non-RP it was $10.5 \pm 8.9$ years. Almost the whole study population $(n=61(96.8 \%))$ fulfilled the ACR/EULAR 2013 classification criteria. There were no statistical differences in the presence of telangiectasias, past or current DU, history of SRC, ILD or cardiac involvement, when comparing the two groups. Although there were no statistical differences in positivity to antinuclear antibodies or the observation of a nucleolar pattern in the indirect immunofluorescence, patients with PAH more often had ACA $(n=23,65.7 \%$ vs $n=11$, $39.3 \%, p=0.03)$, but lower positivity against antitopoisomerase I antibodies $(n=3,8.6 \%$ vs $n=9,32.1 \%$, $p=0.01$ ). Arterial hypertension was the most frequent cardiovascular risk factor in the whole group, being identified in 27 patients (42.9\%), followed by dyslipidaemia in 15 patients (23.8\%); however, there were no patients with diabetes mellitus. No statistical differences were identified in the anthropometrical variables. The patients with PAH received less immunosuppressant therapy than the control group, and less treatment with calcium channel blockers. However, there were no statistical differences in the use of specific vasodilator therapy, for which the indication was RP in all cases.

Regarding respiratory parameters, the PAH group had higher FVC percent predicted/DLCO percent predicted than controls $(2.0 \pm 0.7 \%$ vs $1.5 \pm 0.4 \%, p<0.01)$ and shorter 6MWD $(232.8 \pm 76.7 \mathrm{~m}$ vs $322.4 \pm 105.0 \mathrm{~m}$, $p=0.01$ ) (Table 2). Advanced WHO functional classes III/IV were more common in patients with PAH $(n=15(42.9 \%))$, than in the group with no $\mathrm{PH}(n=2$ $(7.1 \%))(p<0.01)$. There were higher NT-proBNP and serum urate levels and higher prevalence of right axis deviation on ECG in the PAH group. In relation to echocardiographic data, patients with PAH had a greater RA area; moreover, they presented with higher TRV and RVSP than patients with no $\mathrm{PH}$. Therefore, there were statistically significant differences between $\mathrm{PAH}$ and without $\mathrm{PH}$ patients in seven out of eight variables considered in DETECT algorithm.

RHC in the PAH group was characterized by superior mean PAP (Table 3). Specifically, the median (IQR) of mPAP was $42.0(33.0-50.0) \mathrm{mmHg}$ in patients with $\mathrm{PAH}$, while it was 20.5 (17.0 to 23.0) $\mathrm{mmHg}$ in the group with no PH $(p<0.001)$. Furthermore, TPG was increased in patients with $\mathrm{PAH}$, but $\mathrm{CO}$ was lower in those patients. The PAH group had higher pulmonary vascular resistance, with lower $\mathrm{SvO} 2$ and $\mathrm{SaO} 2$ during the RHC, compared with the group with no $\mathrm{PH}$.

\section{Comparisons of the DETECT algorithm and the ESC/ERS 2009 guidelines}

The DETECT algorithm steps are represented in Table 4. After step 1 of the algorithm 35 patients in the PAH group $(100 \%)$ would have been referred to echocardiography compared to 24 in the group without $\mathrm{PH}(85.7 \%)$ ( $p=$ 0.03). Following the echocardiography results, RHC would have been recommended in all 35 patients in the $\mathrm{PAH}$ group (100\%), while this was only the case in 16 
Table 1 Demographic data and baseline characteristics

\begin{tabular}{|c|c|c|c|c|}
\hline & $\begin{array}{l}\text { All patients } \\
(n=63)\end{array}$ & $\begin{array}{l}\text { PAH patients } \\
(n=35)\end{array}$ & $\begin{array}{l}\text { No PH patients } \\
(n=28)\end{array}$ & $P$ value \\
\hline Female $^{a}$ & $59(93.7)$ & $34(97.1)$ & $25(89.3)$ & 0.31 \\
\hline Age, years ${ }^{b}$ & $62.4( \pm 11.6)$ & $64.4( \pm 10.8)$ & $59.9( \pm 12.4)$ & 0.13 \\
\hline $\operatorname{DCSSc}^{\mathrm{a}}$ & $10(15.9)$ & $4(11.4)$ & $6(21.4)$ & 0.31 \\
\hline Time from first symptom, years ${ }^{b}$ & $18.6( \pm 12.3)$ & $19.6( \pm 11.2)$ & $17.2( \pm 13.7)$ & 0.29 \\
\hline Time from first non-RP symptom, years ${ }^{b}$ & $10.5( \pm 8.9)$ & $9.7( \pm 9.4)$ & $11.5( \pm 8.2)$ & 0.21 \\
\hline ACR/EULAR 2013 classification criteria ${ }^{a}$ & $61(96.8)$ & $34(97.1)$ & $27(96.4)$ & 1.0 \\
\hline Telangiectasias $^{a}$ & $59(93.7)$ & $33(94.3)$ & $26(92.9)$ & 1.0 \\
\hline Digital ulcers ${ }^{a}$ & $35(55.6)$ & $20(57.1)$ & $15(53.6)$ & 0.77 \\
\hline Scleroderma renal crisis $^{a}$ & $2(3.2)$ & $2(5.7)$ & $0(0)$ & 0.49 \\
\hline Interstitial lung disease ${ }^{a}$ & $32(50.8)$ & $19(54.3)$ & $12(42.9)$ & 0.45 \\
\hline Cardiac involvement ${ }^{a}$ & $26(41.3)$ & $17(48.6)$ & $9(32.1)$ & 0.18 \\
\hline Antinuclear antibodies ${ }^{a}$ & $62(98.4)$ & $34(97.1)$ & $28(100)$ & 1.0 \\
\hline $\mathrm{ACA}^{\mathrm{a}}$ & $34(54.0)$ & $23(65.7)$ & $11(39.3)$ & 0.03 \\
\hline Anti-Scl-70 & $12(19.0)$ & $3(8.6)$ & $9(32.1)$ & 0.01 \\
\hline Nucleolar IIF pattern ${ }^{\mathrm{a}}$ & $4(6.3)$ & $3(8.6)$ & $1(3.6)$ & 0.62 \\
\hline Arterial hypertension ${ }^{a}$ & $27(42.9)$ & $14(40)$ & $13(43.4)$ & 0.60 \\
\hline Dyslipidaemia $^{a}$ & $15(23.8)$ & $6(17.1)$ & $9(32.1)$ & 0.16 \\
\hline Diabetes mellitus $^{\mathrm{a}}$ & $0(0)$ & $0(0)$ & $0(0)$ & NA \\
\hline Immunosuppressant therapy ${ }^{a}$ & $25(39.7)$ & $8(22.9)$ & $17(60.7)$ & $<0.01$ \\
\hline Prednisone $e^{a}$ & 19 (30.2) & $7(20.0)$ & $12(40.9)$ & 0.04 \\
\hline Sodium mycophenolate ${ }^{a}$ & $7(11.1)$ & $1(2.9)$ & $6(21.4)$ & 0.03 \\
\hline Azathioprine & $3(4.8)$ & $0(0)$ & $3(10.7)$ & 0.08 \\
\hline IV cyclophosphamide ${ }^{a}$ & $12(19.0)$ & $3(8.6)$ & $9(32.1)$ & 0.01 \\
\hline Calcium channel blocker ${ }^{a}$ & $33(52.4)$ & $14(40.0)$ & $19(67.9)$ & 0.02 \\
\hline Specific vasodilator therapy ${ }^{a}$ & $13(20.6)$ & $7(20.0)$ & $6(21.4)$ & 0.88 \\
\hline IV prostanoids ${ }^{a}$ & $1(1.6)$ & $1(2.9)$ & $0(0)$ & 1.0 \\
\hline ERA $^{a}$ & $10(15.9)$ & $5(14.3)$ & $5(17.9)$ & 0.74 \\
\hline PDE5 $I^{a}$ & $5(7.9)$ & $2(5.7)$ & $3(10.7)$ & 0.64 \\
\hline
\end{tabular}

PAH pulmonary arterial hypertension, $P H$ pulmonary hypertension, dCSSC diffuse cutaneous systemic sclerosis, ACR/EULAR American College of Rheumatology/ European League Against Rheumatism, RP Raynaud's phenomenon, ACA anticentromere antibodies, IIF indirect immunofluorescence, NA not applicable, IV intravenous, ERA endothelin receptor antagonist, PDE5 I phosphodiesterase type- 5 inhibitor. ${ }^{a}$ Data are shown as number (\%) for categorical variables. ${ }^{b}$ Data are shown as mean $( \pm S D)$

subjects $(57.1 \%)$ in patients with no $\mathrm{PH}(p<0.001)$. However, based on the ESC/ERS 2009 guidelines, 32 patients with $\mathrm{PAH}(91.4 \%)$ and 4 patients in the group without $\mathrm{PH}(14.3 \%)$ would have been referred for RHC. The RHC referral ratio was higher using DETECT than it was using the ESC/ERS guidelines. The main reasons for not referring these patients for RHC using the ESC/ERS 2009 guidelines would have been that 12 patients had TRV $>2.8$ to $\leq 3.4 \mathrm{~m} / \mathrm{s}$ but with no symptoms, 5 patients presented with TRV $\leq 2.8 \mathrm{~m} / \mathrm{s}$ with symptoms but with no additional echocardiographic signs of $\mathrm{PH}$, and another 10 patients had TRV $\leq 2.8 \mathrm{~m} / \mathrm{s}$ with no symptoms and no additional echocardiographic signs of $\mathrm{PH}$. There would have been no missed diagnosis of PAH with DETECT, but using the ESC/ERS guidelines it would have reached $8.5 \%$ (Table 5). The sensitivity $(95 \% \mathrm{CI})$ of the DETECT algorithm was $100 \%(90.1-100)$ compared to sensitivity of $91.4 \%$ (77.6-97.0) using the ESC/ERS 2009 guidelines. The specificity was lower with DETECT at $42.9 \%(26.5-60.9)$ whereas it was 85.7\% (68.2-94.3) using the ESC/ERS 2009 guidelines. No statistical differences were found in PPV, which was $68.6 \%$ (55.0-79.7) using DETECT compared to 88.9\% (74.7-95.6) using the ESC/ERS 2009 guidelines. However, NPV reached 100\% (75.7-100) using the DETECT algorithm, while using the ESC/ERS 2009 guidelines it was $88.9 \%$ (71.9-96.1). 
Table 2 Respiratory, laboratory and echocardiography data

\begin{tabular}{|c|c|c|c|c|}
\hline & $\begin{array}{l}\text { All patients } \\
(n=63)\end{array}$ & $\begin{array}{l}\text { PAH patients } \\
(n=35)\end{array}$ & $\begin{array}{l}\text { No PH patients } \\
(n=28)\end{array}$ & $P$ value \\
\hline \multicolumn{5}{|l|}{ Pulmonary function tests } \\
\hline FVC, \% predicted ${ }^{b}$ & $75.2( \pm 16.4)$ & $75.6( \pm 15.5)$ & $74.7( \pm 17.8)$ & 0.86 \\
\hline DLCO, $\%$ predicted $^{\mathrm{b}}$ & $46.3( \pm 14.2)$ & $41.5( \pm 13.9)$ & $51.0( \pm 13.1)$ & 0.01 \\
\hline FVC\%/DLCO\% ${ }^{\mathrm{b}}$ & $1.8( \pm 0.6)$ & $2.0( \pm 0.7)$ & $1.5( \pm 0.4)$ & $<0.01$ \\
\hline $6 \mathrm{MWD}, \mathrm{m}^{\mathrm{b}}$ & $256.5( \pm 92.5)$ & $232.8( \pm 76.7)$ & $322.4( \pm 105.0)$ & 0.01 \\
\hline WHO functional class III/IV & $17(27.0)$ & $15(42.9)$ & $2(7.1)$ & $<0.01$ \\
\hline \multicolumn{5}{|l|}{ Laboratory } \\
\hline NT-proBNP, pg/mL ${ }^{c}$ & 198 (41 to 647) & 1271 (580 to 3154) & 87 (32 to 202) & $<0.001$ \\
\hline Serum urate, $\mathrm{mg} / \mathrm{dL}^{\mathrm{b}}$ & $5.6( \pm 1.9)$ & $6.8( \pm 1.9)$ & $4.6( \pm 1.0)$ & $<0.001$ \\
\hline Right axis in $\mathrm{ECG}^{\mathrm{a}}$ & $18(28.6)$ & $10(28.6)$ & $1(3.6)$ & 0.01 \\
\hline \multicolumn{5}{|l|}{ Echocardiography } \\
\hline LVEF, $\%^{c}$ & $60.0(59.0$ to 65.0$)$ & 60.0 (58.5 to 65.0$)$ & 62.0 (59.7 to 65.0) & 0.43 \\
\hline TAPSE, mm ${ }^{b}$ & $19.4( \pm 3.9)$ & $19.1( \pm 4.6)$ & $19.8( \pm 3.0)$ & 0.55 \\
\hline $\mathrm{RA}$ area, $\mathrm{cm} 2^{\mathrm{c}}$ & 16.0 (13.0 to 21.0$)$ & 17.0 (15.0 to 22.7$)$ & 14.0 (12.0 to 16.0$)$ & $<0.01$ \\
\hline TRV, $\mathrm{m} / \mathrm{s}^{\mathrm{b}}$ & $3.5( \pm 0.7)$ & $4.0( \pm 0.6)$ & $2.8( \pm 0.3)$ & $<0.001$ \\
\hline RVSP, $\mathrm{mmHg}^{\mathrm{c}}$ & 59.5 (44.0 to 76.2$)$ & $73.0(61.0$ to 85.0$)$ & $44.0(37.0$ to 51.0$)$ & $<0.001$ \\
\hline
\end{tabular}

PAH pulmonary arterial hypertension, $P H$ pulmonary hypertension, FVC forced vital capacity, DLCO diffusing capacity for carbon monoxide, 6MWD 6-minute walking distance, WHO World Health Organization, NT-proBNP N-terminal pro-brain natriuretic peptide, ECG electrocardiography, LVEF left ventricular ejection fraction, TAPSE tricuspid annular plane systolic excursion, RA right atrium, TRV tricuspid regurgitant velocity, RVSP right ventricular systolic pressure. ${ }^{a} D a t a$ are shown as number (\%) for categorical variables. ${ }^{b}$ Data are shown as mean $( \pm \mathrm{SD}) .{ }^{\mathrm{C}} \mathrm{Data}$ are shown as median (IQR)

As a strategy to identify mPAP $\geq 21 \mathrm{mmHg}$ (both BoPAP and PAH), the DETECT algorithm had superior sensitivity of $93.9 \%(83.5-97.9)$ and NPV of $75.0 \%$ (46.8-91.1) compared to ESC/ERS guidelines for which the sensitivity and NPV was $69.4 \%(55.5-80.5)$ and 44.4\% (27.6-62.7), respectively. Furthermore, DETECT missed $6.1 \%$ of diagnoses of mPAP $\geq 21$, whereas using the ESC/ERS 2009 guidelines the percentage was increased to $30.6 \%$. In fact, analysing only patients with BoPAP, there were 3 out of 14 (21.1\%) missed diagnoses using DETECT, whereas there were 12 out of 14 (85.7\%) missed using the ESC/ERS 2009 guidelines. However, specificity and PPV were slightly lower using the DETECT algorithm, at $64.3 \%$ and $90.2 \%$ compared to $85.7 \%$ and $94.4 \%$, respectively, using the ESC/ERS guidelines.

To investigate the capacity for the detection of any type of $\mathrm{PH}$, the whole cohort of patients $(n=83)$ with a first RHC were studied, regardless of whether they met the inclusion or exclusion criteria for application of the DETECT algorithm: $1.9 \%$ of diagnoses of $\mathrm{PH}$ were missed using the DETECT algorithm compared with

Table 3 Haemodynamic characteristics on right heart catheterization

\begin{tabular}{|c|c|c|c|c|}
\hline & $\begin{array}{l}\text { All patients } \\
(n=63)\end{array}$ & $\begin{array}{l}\text { PAH patients } \\
(n=35)\end{array}$ & $\begin{array}{l}\text { No PH patients } \\
(n=28)\end{array}$ & $P$ value \\
\hline Mean PAP, mmHg & 31.0 (21.0 to 44.0$)$ & 42.0 (33.0 to 50.0$)$ & 20.5 (17.0 to 23.0$)$ & $<0.001$ \\
\hline PAWP, $\mathrm{mmHg}^{\mathrm{a}}$ & $9.6( \pm 4.0)$ & $9.7( \pm 4.8)$ & $9.5( \pm 3.4)$ & 0.90 \\
\hline RAP, $m m H g^{b}$ & 5.0 (2.5 to 8.5$)$ & 5.0 (3.0 to 10.0$)$ & 4.5 (2.0 to 7.0$)$ & 0.14 \\
\hline TPG, $m m \mathrm{mg}^{\mathrm{a}}$ & $20.0( \pm 13.4)$ & $31.4( \pm 11.8)$ & $10.6( \pm 3.9)$ & $<0.001$ \\
\hline Cardiac output, L/min ${ }^{\mathrm{b}}$ & 3.5 (2.9 to 4.5$)$ & 3.4 (2.8 to 4.0$)$ & $3.9(2.9$ to 5.1$)$ & 0.05 \\
\hline$P V R, W U^{a}$ & $6.6( \pm 4.8)$ & $9.9( \pm 4.6)$ & $3.2( \pm 1.6)$ & $<0.001$ \\
\hline$S V R, W U^{a}$ & $26.9( \pm 10.3)$ & $28.6( \pm 9.7)$ & $25.2( \pm 11.0)$ & 0.42 \\
\hline $\mathrm{SvO} 2, \%^{\mathrm{a}}$ & $66.3( \pm 8.1)$ & $61.8( \pm 8.3)$ & $71.0( \pm 4,7)$ & $<0.001$ \\
\hline $\mathrm{SaO} 2, \%^{\mathrm{a}}$ & $93.5( \pm 4.0)$ & $91.2( \pm 3.7)$ & $96.1( \pm 2.5)$ & $<0.001$ \\
\hline
\end{tabular}

$P A H$ pulmonary arterial hypertension, $P H$ pulmonary hypertension, $P A P$ pulmonary artery pressure, $P A W P$ pulmonary artery wedge pressure, $R A P$ right atrial pressure, TPG transpulmonary pressure gradient, $P V R$ pulmonary vascular resistance, WU Wood units, SVR systemic vascular resistance, SVO2 mixed venous oxygen saturation, $\mathrm{SaO} 2$ arterial oxygen saturation. ${ }^{\mathrm{a}}$ Data are shown as mean $( \pm \mathrm{SD}) .{ }^{\mathrm{b}}$ Data are shown as median (IQR) 
Table 4 Comparisons of the DETECT algorithm and the ESC/ERS 2009 guidelines

\begin{tabular}{|c|c|c|c|c|c|c|c|c|c|}
\hline & \multicolumn{3}{|c|}{$\begin{array}{l}\text { PAH vs no PH patients } \\
(n=63)\end{array}$} & \multicolumn{3}{|c|}{$\begin{array}{l}\text { Patients with } \mathrm{mPAP} \geq 21 \text { vs } \mathrm{mPAP}<21 \mathrm{mmg} \\
(n=63)\end{array}$} & \multicolumn{3}{|c|}{$\begin{array}{l}\text { PH vs no PH patients } \\
(n=83)\end{array}$} \\
\hline & $\begin{array}{l}\mathrm{PAH} \\
(n=35)\end{array}$ & $\begin{array}{l}\text { No PH } \\
(n=28)\end{array}$ & $P$ value & $\begin{array}{l}\mathrm{mPAP} \geq 21 \mathrm{mmHg} \\
(n=49)\end{array}$ & $\begin{array}{l}\text { mPAP }<21 \mathrm{mmg} \\
(n=14)\end{array}$ & $P$ value & $\begin{array}{l}\mathrm{PH} \\
(n=52)\end{array}$ & $\begin{array}{l}\text { No PH } \\
(n=31)\end{array}$ & $P$ value \\
\hline \multicolumn{10}{|l|}{ DETECT algorithm } \\
\hline Score step $1^{\mathrm{b}}$ & $330.0( \pm 25.3)$ & $313.7( \pm 17.5)$ & $<0.01$ & $326.9( \pm 22.8)$ & $308.6( \pm 20.8)$ & $<0.01$ & $327.9( \pm 23.6)$ & $311.8( \pm 17.6)$ & $<0.01$ \\
\hline Indication of Echo ${ }^{a}$ & $35(100)$ & $24(85.7)$ & 0.03 & $49(100)$ & $10(71.4)$ & $<0.01$ & $51(98.1)$ & $24(77.4)$ & $<0.01$ \\
\hline Score step $2^{b}$ & $60.2( \pm 11.3)$ & $37.3( \pm 8.4)$ & $<0.001$ & $54.7( \pm 13.3)$ & $33.5( \pm 8.8)$ & $<0.001$ & $56.4( \pm 12.4)$ & $36.5( \pm 8.4)$ & $<0.001$ \\
\hline RHC recommendation ${ }^{a}$ & $35(100)$ & $16(57.1)$ & $<0.001$ & $46(93.9)$ & $5(35.7)$ & $<0.001$ & $51(98.1)$ & $17(54.8)$ & $<0.001$ \\
\hline \multicolumn{10}{|l|}{ ESC/ERS 2009 guidelines } \\
\hline $\mathrm{RHC}$ recommendation ${ }^{\mathrm{a}}$ & $32(91.4)$ & $4(14.3)$ & $<0.001$ & $34(69.4)$ & $2(14.3)$ & $<0.001$ & $42(80.8)$ & $4(12.9)$ & $<0.001$ \\
\hline
\end{tabular}

$P A H$ pulmonary arterial hypertension, $P H$ pulmonary hypertension, mPAP mean pulmonary artery pressure, Echo echocardiography, $R H C$ right heart catheterization, ESC/ERS European Society of Cardiology and the European Respiratory Society. ${ }^{a}$ Data are shown as number (\%) for categorical variables. ${ }^{b}$ Data are shown as mean ( \pm SD)

19.2\% missed using the ESC/ERS 2009 guidelines. Moreover, sensitivity and NPV were greater at $98.1 \%$ and 93.3\% using the DETECT method, compared with $80.8 \%$ and $73.0 \%$, respectively, using the ESC/ERS guidelines. Nevertheless, specificity and PPV were again slightly inferior at $45.2 \%$ and $75.0 \%$ when applying the DETECT algorithm, whereas the values were $87.1 \%$ and $91.3 \%$, respectively, using in the ESC/ERS guidelines.

\section{Discussion}

The present retrospective study compared the application of the DETECT algorithm with the ESC/ERS 2009 guidelines in patients with $\mathrm{PAH}$ and patients without $\mathrm{PH}$, who had undergone RHC. The DETECT programme had greater sensitivity, the RHC would have been recommended in all patients suffering from PAH, and also superior NPV compared to the ESC/ERS guidelines. Nevertheless, the ESC/ERS 2009 guidelines had higher specificity and PPV than the DETECT algorithm. Furthermore, the DETECT algorithm had higher percentage sensitivity and NPV both for the detection of patients with $\mathrm{mPAP} \geq 21$ and for patients with any type of $\mathrm{PH}$, although specificity and PPV were lower.

For the application of the DETECT algorithm it is necessary to meet the inclusion criteria, so patients must present with a duration of SSc longer than 3 years from the first non-RP symptom and DLCO $<60 \%$ predicted. This was to increase the specificity of the screening method, due to the fact that $<10 \%$ of a cohort of 243 patients with SSc-PH have been found to present with DLCO $>60 \%$ [19]. Furthermore, patients could not fulfil the exclusion criteria such as previous $\mathrm{PH}$ diagnosed by RHC, forced vital capacity (FVC) $<40 \%$ or the involvement of left heart disease [12]. Nevertheless, DETECT does not establish the periodicity of an assessment by this method, it has not been evaluated over a monitoring period in a cohort of patients and its ability to predict mPAP $\geq 21 \mathrm{mmHg}$ or any type of $\mathrm{PH}$ have not been explored. As a consequence of this work, the new ESC/ ESR 2015 guidelines were recently published, which strengthen the recommendation for annual screening of $\mathrm{PH}$ in this set of patients with SSc and introduce the

Table 5 Observation of PAH detection programs

\begin{tabular}{|c|c|c|c|c|c|c|c|}
\hline & & RHC referral rate, \% & Missed diagnoses, \% & Sensitivity \% & Specificity \% & PPV \% & NPV \% \\
\hline \multirow[t]{2}{*}{ PAH vs no PH patients } & $\begin{array}{l}\text { DETECT algorithm } \\
(95 \% \mathrm{Cl})\end{array}$ & $\begin{array}{l}51 / 63,80.9 \% \\
-\end{array}$ & $\begin{array}{l}0 / 35,0 \% \\
-\end{array}$ & $\begin{array}{l}100 \% \\
(90.1-100)\end{array}$ & $\begin{array}{l}42.9 \% \\
(26.5-60.9)\end{array}$ & $\begin{array}{l}68.6 \% \\
(55.0-79.7)\end{array}$ & $\begin{array}{l}100 \% \\
(75.7-100)\end{array}$ \\
\hline & $\begin{array}{l}\text { ESC/ERS guidelines } \\
(95 \% \mathrm{Cl})\end{array}$ & $\begin{array}{l}36 / 63,57.1 \% \\
-\end{array}$ & $\begin{array}{l}3 / 35,8.5 \% \\
-\end{array}$ & $\begin{array}{l}91.4 \% \\
(77.6-97.0)\end{array}$ & $\begin{array}{l}85.7 \% \\
(68.5-94.3)\end{array}$ & $\begin{array}{l}88.9 \% \\
(74.7-95.6)\end{array}$ & $\begin{array}{l}88.9 \% \\
(71.9-96.1)\end{array}$ \\
\hline \multirow[t]{2}{*}{$\begin{array}{l}\text { Patients with mPAP } \geq 21 \text { vs } \\
m P A P<21 \mathrm{mmg}\end{array}$} & $\begin{array}{l}\text { DETECT algorithm } \\
(95 \% \mathrm{Cl})\end{array}$ & $\begin{array}{l}51 / 63,80.9 \% \\
-\end{array}$ & $\begin{array}{l}3 / 49,6.1 \% \\
-\end{array}$ & $\begin{array}{l}93.9 \% \\
(83.5-97.9)\end{array}$ & $\begin{array}{l}64.3 \% \\
(38.8-83.7)\end{array}$ & $\begin{array}{l}90.2 \% \\
(79.0-95.7)\end{array}$ & $\begin{array}{l}75.0 \% \\
(46.8-91.1)\end{array}$ \\
\hline & $\begin{array}{l}\text { ESC/ERS guidelines } \\
(95 \% \mathrm{Cl})\end{array}$ & $\begin{array}{l}36 / 63,57.1 \% \\
-\end{array}$ & $\begin{array}{l}15 / 49,30.6 \% \\
-\end{array}$ & $\begin{array}{l}69.4 \% \\
(55.5-80.5)\end{array}$ & $\begin{array}{l}85.7 \% \\
(60.1-96.0)\end{array}$ & $\begin{array}{l}94.4 \% \\
(81.9-98.5)\end{array}$ & $\begin{array}{l}44.4 \% \\
(27.6-62.7)\end{array}$ \\
\hline \multirow[t]{2}{*}{$\mathrm{PH}$ vs no PH patients } & $\begin{array}{l}\text { DETECT algorithm } \\
(95 \% \mathrm{Cl})\end{array}$ & $68 / 83,81.9 \%$ & $\begin{array}{l}1 / 52,1.9 \% \\
-\end{array}$ & $\begin{array}{l}98.1 \% \\
(89.9-99.7)\end{array}$ & $\begin{array}{l}45.2 \% \\
(29.2-62.2)\end{array}$ & $\begin{array}{l}75.0 \% \\
(63.6-83.8)\end{array}$ & $\begin{array}{l}93.3 \% \\
(70.2-98.8)\end{array}$ \\
\hline & $\begin{array}{l}\text { ESC/ERS guidelines } \\
(95 \% \mathrm{Cl})\end{array}$ & $\begin{array}{l}46 / 83,55.4 \% \\
-\end{array}$ & $10 / 52,19.2 \%$ & $\begin{array}{l}80.8 \% \\
(68.1-89.2)\end{array}$ & $\begin{array}{l}87.1 \% \\
(71.1-94.9)\end{array}$ & $\begin{array}{l}91.3 \% \\
(79.7-96.6)\end{array}$ & $\begin{array}{l}73.0 \% \\
(57.0-84.6)\end{array}$ \\
\hline
\end{tabular}

Data shown as number (\%). RHC right heart catheterization, $P P V$ positive predictive value, NPV negative positive value, $P A H$ pulmonary arterial hypertension, $\mathrm{PH}$ pulmonary hypertension, $\mathrm{Cl}$ confidence interval, mPAP mean pulmonary artery pressure, ESC/ERS European Society of Cardiology and the European Respiratory Society 
DETECT algorithm as a valid method to be performed in this group of patients based on the evidence demonstrated [15].

Compared to the study of Coghlan et al., patients in our cohort had a surprisingly higher prevalence of telangiectasias and ACA antibodies. Almost $60 \%$ of patients with PAH presented with WHO functional class I or II and mild reduced 6MWD comparable to the detection cohorts of previous studies that have focused on early PAH diagnosis $[10,12]$. This fact seems to reflect that patients in our study were referred promptly for RHC as a result of active and early suspicion of PAH during monitoring. In the present paper we describe similar sensitivity, specificity and NPV values, although with a higher RHC referral ratio and PPV using the DETECT algorithm than in the original work. However, regarding the application of ESC/ERS 2009 guidelines we report higher sensitivity, specificity and PPV values and a higher RHC referral ratio than Coghlan et al. This may be explained due to the fact that the main indication for performing RHC in our study was the presence of an abnormal echocardiographic result, suggesting the presence of PAH. Furthermore, the high RHC referral ratio may be justified because the study was conducted in a selected population of patients at high risk of PAH based on clinical, pulmonary function test and echocardiographic parameters.

Few groups have published on the application of the DETECT algorithm. Hao et al. analysed the DETECT algorithm in patients from the multicentre Australian Scleroderma Cohort Study (ASCS) along with the Australian Scleroderma Interest Group (ASIG) algorithm and the ESC/ERS 2009 guidelines [20, 21]. The authors found higher sensitivity and NPV using the DETECT or the ASIG algorithm than they did using the ESC/ERS guidelines, which we can confirm in our study. Surprisingly, the ASIG protocol had superior specificity to the DETECT algorithm and even to the ESC/ERS guidelines, which contrasts with the values of $48 \%$ and $69 \%$, respectively, that were previously published [12]. The authors reported that nine patients did not meet the criterion of DLCO $<60 \%$ or the criterion for disease duration, and this may explain the lower specificity of the DETECT algorithm [21]. Furthermore, the DETECT and ASIG screening methods had the highest sensitivity and specificity to identify both precapillary $\mathrm{PH}$ and any group of $\mathrm{PH}$, results that we have corroborated in our work. In the present work the ASIG programme was not analysed due to the fact that this method is not based on evidence and has not been well-validated in European cohorts.

Recently, a Czech scleroderma group designed a modified DETECT algorithm, in which a right ventricular outflow tract is evaluated instead of RA area [22]. Using this modified DETECT programme the RHC referral ratio was $41.4 \%$ compared to $24.1 \%$ using the ESC/ERS guidelines. Interestingly, although only $11 / 58$ patients (18.9\%) had undergone RHC, in patients who were recommended by the modified DETECT algorithm there were also other types of $\mathrm{PH}$ diagnosed, such as $\mathrm{PH}$ due to left heart disease and PH due to ILD. Therefore, this article suggests that the DETECT algorithm would be useful for recommending RHC for diagnosing other types of $\mathrm{PH}$ according to the WHO classification.

Although there are some discrepancies on the prognostic role of BoPAP, a study has been recently published evidencing a higher risk of mortality and hospitalization in US veteran patients with BoPAP (defined as 19-24 $\mathrm{mmHg}$ ) [23]. Consequently, the study highlights the relevance of diagnosing BoPAP in selected groups of patients such as those with scleroderma. In a post-hoc analysis of the DETECT study, the authors demonstrated that patients with BoPAP had a higher FVC/DLCO rate, and higher TRV and NTproBNP levels than in patients with normal mPAP [16]. Although the paper does not evaluate the application of DETECT in both groups of patients, it would support the increment of the specificity of this programme identified in our work when studying patients with mPAP $\geq 21$ versus $\mathrm{mPAP}<21 \mathrm{mmg}$, compared to the $\mathrm{PAH}$ versus no $\mathrm{PH}$ strategy. In the set of patients with SSc, identifying BoPAP in the first RHC was demonstrated as a high risk factor for developing $\mathrm{PH}$, with a hazard ratio of 3.7 during follow up compared to patients with $\mathrm{mPAP}<21 \mathrm{mmHg}$ [24]. In this line, in a multicentre prospective SSc cohort, the Pulmonary Hypertension Assessment and Recognition of Outcomes in Scleroderma (PHAROS) study group reported that $55 \%$ of patients with BoPAP progressed to $\mathrm{PH}$, whereas in the group of patients with $\mathrm{mPAP}<21 \mathrm{mmHg}$ this was $32 \%$, over a mean 25.7 -month period of monitoring [25]. Having established the relevance of identifying patients with SSc and BoPAP for close supervision, this is the first paper that demonstrates the accuracy of the DETECT algorithm in the identification of patients with $\mathrm{mPAP} \geq 21$.

The main limitation of the present study was the retrospective design. RHC was not performed in the whole cohort of patients with SSc, therefore some mild forms of PAH may have been undiagnosed. In the same line, although the periodicity of performing the screening methods is not well established, these were not carried out in the whole cohort, which may not reflect the real referral rate for RHC.

\section{Conclusions}

Pulmonary arterial hypertension in one of the leading causes of death in patients with SSc, and its early 
diagnosis has demonstrated increased survival rates. The present study supports the DETECT algorithm as an excellent screening method due to its high sensitivity and NPV, which minimizes the number of missed diagnoses of previous recommendations. Furthermore, our data suggest the DETECT algorithm is also accurate either for an early diagnosis of borderline mPAP, patients who are at highest risk of developing $\mathrm{PAH}$, or the diagnosis of any type of $\mathrm{PH}$.

\begin{abstract}
Abbreviations
6MWD: 6-Minute walking distance; ACA: Anticentromere antibodies; ACR: American College of Rheumatology; ANA: Antinuclear antibodies; ASCS: Australian Scleroderma Cohort Study; ASIG: Australian Scleroderma Interest Group; BoPAP: Borderline median pulmonary arterial pressure; Cl: Confidence interval; CO: Cardiac output; dcSSc: Diffuse cutaneous systemic sclerosis; DLCO: Diffusing capacity for carbon monoxide; DU: Digital ulcers; ECG: Electrocardiography; ERA: Endothelin receptor antagonist; ESC/ ERS: European Society of Cardiology and the European Respiratory Society; EULAR: European League Against Rheumatism; FVC: Forced vital capacity; HR: Hazard ratio; HRCT: High-resolution computed tomography; IIF: Indirect immunofluorescence; ILD: Interstitial lung disease; IQR: Interquartile range; IV: Intravenous; ICSSc: limited cutaneous systemic sclerosis; LHD: Left heart disease; LVEF: Left ventricular ejection fraction; mPAP: Median pulmonary arterial pressure; NPV: Negative predictive value; NT-proBNP: N-terminal pro-brain natriuretic peptide; PAH: Pulmonary arterial hypertension; PAWP: Pulmonary artery wedge pressure; PDE5 I: Phosphodiesterase type-5 inhibitor; PFT: Pulmonary function test; PH: Pulmonary hypertension; PHAROS: Pulmonary Hypertension Assessment and Recognition of Outcomes in Scleroderma; PPV: Positive predictive value; PVR: Pulmonary vascular resistance; RA: Right atrium; RAP: Right atrial pressure; RHC: Right heart catheterization; RP: Raynaud's phenomenon; RVSP: Right ventricular systolic pressure; SaO2: Arterial oxygen saturation; SD: Standard deviation; SRC: Scleroderma renal crisis; SSc: Systemic sclerosis; ssSSc: Sine scleroderma systemic sclerosis; SVO2: Mixed venous oxygen saturation; SVR: Systemic vascular resistance; TAPSE: Tricuspid annular plane systolic excursion; TPG: Transpulmonary pressure gradient; TRV: Tricuspid regurgitant velocity; vs: Versus; WHO: World Health Organization; WU: Wood units
\end{abstract}

\section{Acknowledgements}

The authors thank the patients for their participation

\section{Funding}

This work was funded by Instituto de Salud Carlos III, grant PI16/02088 co-financed by the European Regional Development Fund (ERDF). This work was supported by an educational unrestricted scholarship granted by Actelion Pharmaceuticals. AGDC was supported by the Contratos Predoctorales de Formación en Investigación (PFIS) grant from Instituto de Salud Carlos III (Fl14/00643)

\section{Availability of data and materials}

The datasets analysed during the current study are available from the corresponding author on reasonable request.

\section{Authors' contributions}

AGDC made substantial contributions to study conception and design, acquisition, analysis and interpretation of data, drafting the article and approval of the final manuscript. ELCM and GG made substantial contributions to study conception and design, analysis and interpretation of data, revising the manuscript critically for important intellectual content and approval of the final manuscript. JFRP, AR, CB, MLM, ED and VFP made substantial contributions to study conception and design, revising the manuscript critically for important intellectual content and approval of the final manuscript. CPSA made substantial contributions to study conception and design, interpretation of data, revising the manuscript critically for important intellectual content and approval of the final manuscript. AGDC and ELCM had full access to all of the data in the study and they both take responsibility for the integrity and accuracy of the data. Funders had no access to the data, were not involved in study design, acquisition, analysis or interpretation of data or writing the manuscript. All authors read and approved the final manuscript.

\section{Competing interests}

The authors declare that they have no competing interests.

Consent for publication

Not applicable.

Ethics approval and consent to participate

This study was approved by the hospital Ethics Committee for Clinical Research and all subjects consented to use of their clinical and laboratory data.

\section{Publisher's Note}

Springer Nature remains neutral with regard to jurisdictional claims in published maps and institutional affiliations.

\section{Author details}

${ }^{1}$ Department of Systemic Autoimmune Diseases, Hospital Universitari Vall d'Hebron, Universitat Autònoma de Barcelona, Passeig Vall d'Hebron 119-129, PC: 08035 Barcelona, Spain. ${ }^{2}$ Department of Cardiology, Hospital Universitari Vall d'Hebron, Universitat Autònoma de Barcelona, Barcelona, Spain. ${ }^{3}$ Department of Pneumology, Hospital Universitari Vall d'Hebron, Universitat Autònoma de Barcelona, Barcelona, Spain.

Received: 25 January 2017 Accepted: 11 May 2017

Published online: 14 June 2017

\section{References}

1. Denton CP, Ong VH. Targeted therapies for systemic sclerosis. Nat Rev Rheumatol. 2013:9:451-64.

2. Allanore Y, Simms R, Distler O, Trojanowska M, Pope J, Denton CP, et al. Systemic sclerosis. Nat Rev Dis Primers. 2015;1:15002.

3. Mukerjee D, St George D, Coleiro B, Knight C, Denton CP, Davar J, et al. Prevalence and outcome in systemic sclerosis associated pulmonary arterial hypertension: application of a registry approach. Ann Rheum Dis. 2003;62: 1088-93.

4. Avouac J, Airo P, Meune C, Beretta L, Dieude P, Caramaschi P, et al. Prevalence of pulmonary hypertension in systemic sclerosis in European Caucasians and meta analysis of 5 studies. J Rheumatol. 2010;37:2290-8.

5. Steen VD, Medsger TA. Changes in causes of death in systemic sclerosis, 1972-2002. Ann Rheum Dis. 2007:66:940-4.

6. Nihtyanova SI, Schreiber BE, Ong VH, Rosenberg D, Moinzadeh P, Coghlan $\mathrm{JG}$, et al. Prediction of pulmonary complications and long-term survival in systemic sclerosis. Arthritis Rheumatol. 2014;66:1625-35.

7. Simeon-Aznar CP, Fonollosa-Pla V, Tolosa-Vilella C, Espinosa-Garriga G, Campillo-Grau M, Ramos-Casals M, et al. Registry of the Spanish Network for Systemic Sclerosis: survival, prognostic factors, and causes of death. Medicine (Baltimore). 2015;94:e1728.

8. Rubenfire M, Huffman MD, Krishnan S, Seibold JR, Schiopu E, McLaughlin W. Survival in systemic sclerosis with pulmonary arterial hypertension has not improved in the modern era. Chest. 2013;144:1282-90.

9. Hachulla E, Gressin V, Guillevin L, Carpentier P, Diot E, Sibilia J, et al. Early detection of pulmonary arterial hypertension in systemic sclerosis: a French nationwide prospective multicenter study. Arthritis Rheum. 2005; 52:3792-800.

10. Humbert M, Yaici A, de Groote P, Montani D, Sitbon O, Launay D, et al. Screening for pulmonary arterial hypertension in patients with systemic sclerosis: clinical characteristics at diagnosis and long-term survival. Arthritis Rheum. 2011;63:3522-30.

11. Galie N, Hoeper MM, Humbert M, Torbicki A, Vachiery JL, Barbera JA, et al. Guidelines for the diagnosis and treatment of pulmonary hypertension: the Task Force for the Diagnosis and Treatment of Pulmonary Hypertension of the European Society of Cardiology (ESC) and the European Respiratory Society (ERS), endorsed by the International Society of Heart and Lung Transplantation (ISHLT). Eur Heart J. 2009:30:2493-537.

12. Coghlan JG, Denton CP, Grunig E, Bonderman D, Distler O, Khanna D, et al. Evidence-based detection of pulmonary arterial hypertension in systemic sclerosis: the DETECT study. Ann Rheum Dis. 2014;73:1340-9. 
13. LeRoy EC, Black C, Fleischmajer R, Jablonska S, Krieg T, Medsger Jr TA, et al. Scleroderma (systemic sclerosis): classification, subsets and pathogenesis. J Rheumatol. 1988;15:202-5.

14. van den Hoogen F, Khanna D, Fransen J, Johnson SR, Baron M, Tyndall A, et al. 2013 classification criteria for systemic sclerosis: an American College of Rheumatology/European League against Rheumatism collaborative initiative. Arthritis Rheum. 2013;65:2737-47.

15. Galie N, Humbert M, Vachiery JL, Gibbs S, Lang I, Torbicki A, et al. 2015 ESC/ ERS Guidelines for the diagnosis and treatment of pulmonary hypertension: The Joint Task Force for the Diagnosis and Treatment of Pulmonary Hypertension of the European Society of Cardiology (ESC) and the European Respiratory Society (ERS): endorsed by: Association for European Paediatric and Congenital Cardiology (AEPC), International Society for Heart and Lung Transplantation (ISHLT). Eur Heart J. 2016;37:67-119.

16. Visovatti SH, Distler O, Coghlan JG, Denton CP, Grunig E, Bonderman D, et al. Borderline pulmonary arterial pressure in systemic sclerosis patients: a post-hoc analysis of the DETECT study. Arthritis Res Ther. 2014;16:493.

17. Simeon-Aznar CP, Tolosa-Vilella C, Gabarro-Julia L, Campillo-Grau M, Guillen Del Castillo A, Fonollosa-Pla V, et al. Systemic sclerosis sine scleroderma and limited cutaneous systemic sclerosis: similarities and differences. Clin Exp Rheumatol. 2014;32:S-33-40.

18. DETECT - DETECTion of PAH in SSC. http://detect-pah.com. Accessed 25 Apr 2016

19. Schwaiger JP, Khanna D, Gerry Coghlan J. Screening patients with scleroderma for pulmonary arterial hypertension and implications for other at-risk populations. Eur Respir Rev. 2013;22:515-25.

20. Thakkar V, Stevens W, Prior D, Youssef P, Liew D, Gabbay E, et al. The inclusion of $\mathrm{N}$-terminal pro-brain natriuretic peptide in a sensitive screening strategy for systemic sclerosis-related pulmonary arterial hypertension: a cohort study. Arthritis Res Ther. 2013;15:R193.

21. Hao Y, Thakkar V, Stevens W, Morrisroe K, Prior D, Rabusa C, et al. A comparison of the predictive accuracy of three screening models for pulmonary arterial hypertension in systemic sclerosis. Arthritis Res Ther. 2015;17:7.

22. Soukup T, Pudil R, Kubinova K, Hromadkova L, Dusek J, Tosovsky M, et al. Application of the DETECT algorithm for detection of risk of pulmonary arterial hypertension in systemic sclerosis: data from a Czech tertiary centre. Rheumatology (Oxford). 2016:55:109-14.

23. Maron BA, Hess E, Maddox TM, Opotowsky AR, Tedford RJ, Lahm T, et al. Association of borderline pulmonary hypertension with mortality and hospitalization in a large patient cohort: insights from the Veterans Affairs Clinical Assessment, Reporting, and Tracking Program. Circulation. 2016; 133:1240-8.

24. Valerio CJ, Schreiber BE, Handler CE, Denton CP, Coghlan JG. Borderline mean pulmonary artery pressure in patients with systemic sclerosis: transpulmonary gradient predicts risk of developing pulmonary hypertension. Arthritis Rheum. 2013;65:1074-84.

25. Bae S, Saggar R, Bolster MB, Chung L, Csuka ME, Derk C, et al. Baseline characteristics and follow-up in patients with normal haemodynamics versus borderline mean pulmonary arterial pressure in systemic sclerosis: results from the PHAROS registry. Ann Rheum Dis. 2012;71:1335-42.

\section{Submit your next manuscript to BioMed Central and we will help you at every step:}

- We accept pre-submission inquiries

- Our selector tool helps you to find the most relevant journal

- We provide round the clock customer support

- Convenient online submission

- Thorough peer review

- Inclusion in PubMed and all major indexing services

- Maximum visibility for your research

Submit your manuscript at www.biomedcentral.com/submit

) Biomed Central 